\title{
p38 predicts depression and poor outcome in esophageal cancer
}

\author{
YAO CHENG ${ }^{1 *}$, ZHE QIAO $^{1 *}$, CHENGXUE DANG $^{2}$, BIN ZHOU $^{1}$, SHAOMIN LI ${ }^{1}$, \\ WEI ZHANG ${ }^{1}$, JIANTAO JIANG ${ }^{1}$, YONGCHUN SONG ${ }^{2}$, JIN ZHANG ${ }^{1}$ and DONGMEI DIAO ${ }^{2}$ \\ ${ }^{1}$ Department of Thoracic Surgery, The Second Affiliated Hospital, Xi'an Jiaotong University College \\ of Medicine, Xi'an, Shaanxi 710004; ${ }^{2}$ Department of Surgical Oncology, The First Affiliated Hospital, \\ Xi'an Jiaotong University College of Medicine, Xi'an, Shaanxi 710061, P.R. China
}

Received January 15, 2016; Accepted June 9, 2017

DOI: $10.3892 / \mathrm{ol} .2017 .7129$

\begin{abstract}
MAPK) signaling has been implicated in the cancer development and progression. However, the precise mechanism of this association remains unknown. The aim of the present study was to evaluate the association between $\mathrm{p} 38$ and cancer progression, including investigations into the effects on cell proliferation, resistance to thalidomide, indoleamine 2,3-dioxygenase (IDO) expression and prognosis in patients with esophageal cancer. The present retrospective study included patients with stage I-III esophageal cancer. A total of 228 patients with esophageal cancer were recruited to analyze the expression of phosphorylated (p)-p38 and IDO in tumor, and normal tissues through immunohistochemistry. Depression status was measured using the Zung Self-Rating Depression Scale. P38 cDNA was transfected into esophageal cancer cells to assess tumor cell viability, sensitivity to thalidomide treatment and IDO gene expression. Western blotting and flow cytometry was used to analyze protein expression alterations, and apoptosis in esophageal cancer cells. P-p38 protein was expressed in $68.9 \%$ of cancer tissues, and was significantly associated with depressive symptoms, tumor recurrence and poor survival of patients. In vitro experiments revealed that the expression of p-p38 induced esophageal cancer Eca-109 and TE-1 cell viability, and resistance to thalidomide treatment, as well as in the expression of IDO without the application of lipopolysaccharides. Further follow-up of patients revealed that depression was also an independent factor for early recurrence and overall survival rate. Altered p38 MAPK expression was associated with poor outcome in patients with esophageal cancer. p38 may be a potential biomarker for the
\end{abstract}

Correspondence to: Dr Dongmei Diao, Department of Surgical Oncology, The First Affiliated Hospital, Xi'an Jiaotong University College of Medicine, 277 West Yanta Road, Xi'an, Shaanxi 710061, P.R. China

E-mail: diaomei310@163.com

*Contributed equally

Key words: esophageal cancer, p38, depression prediction of depressive symptoms and prognosis in patients with esophageal cancer.

\section{Introduction}

Esophageal cancer (EC) is one of the leading causes of mortality worldwide due to the majority of patients presenting with the advanced stage of the disease at the time of diagnosis and the high incidence of early recurrence following treatment (1). Surgical resection is one of the primary components of multimodality treatment, which unavoidably reduces the quality of life, particularly due to complications, including anastomotic leakage and stenosis (2). Even with the advancement in treatment options, the 5-year survival rate of EC remains low $(3,4)$. As a result, there is a requirement for an effective biomarker for early detection, the development of targeted anticancer therapies and prognostication. Furthermore, a more detailed knowledge of the signaling pathways associated with tumor malignancy would aid in understanding tumor biology and individualizing treatment.

Depression is one of the common psychological disorders observed in patients with cancer, with its prevalence varying between 7.2 and $25.7 \%$ in patients with the advanced stage $(5,6)$. Depression in EC not only reduces the quality of life, but also shortens survival time and prolongs hospitalization $(7,8)$. However, in the majority of cases, depression remains undiagnosed and untreated. The mechanism involved in the development of depression remains unknown (9). Nowadays, although several genes involved in the occurrence and prognosis of depression are known, further information is warranted (10).

The p38 mitogen-activated protein kinase (MAPK) signaling pathway can be activated by dual phosphorylation mediated primarily by MAPK kinase 3 (MKK3) and MKK6 in response to a range of cell stresses, and inflammatory cytokines (11). p38-MAPK signaling has been implicated in the regulation of processes that lead to the development and progression of a variety of cancer types $(12,13)$. Furthermore, in certain other tumor types, the inhibition of p38 enhances sensitivity to chemotherapy $(14,15)$, suggesting that p38 may serve as an oncogene in cancer progression. However, the function of p38 in esophageal cancer remains unclear $(16,17)$. Zhong et al (18) reported that $\mathrm{p} 38 / \mathrm{p} 21$ participates in obatoclax-induced $\mathrm{G}_{1} / \mathrm{G}_{0}$ arrest in esophageal cancer in vitro 
independent of extracellular regulated kinase 1/2. However, whether or not $\mathrm{p} 38$ is able to regulate other biological effects remains unknown. In the present study, the role of p38 MAPK in the development and progression of esophageal cancer was investigated in vitro in order to determine its clinical significance.

Several studies have demonstrated that indoleamine 2,3-dioxygenase (IDO) (19,20), a well-known depression-associated gene, can be upregulated by interferons and lipopolysaccharides (LPS) via the p38 MAPK signaling pathway (21-23). In the present study, whether or not p38 MAPK can increase the expression of IDO directly and aggravate clinical depression in esophageal cancer, was also examined.

\section{Materials and methods}

Tissue samples. A total of 228 surgically resected, unifocal, primary human esophageal cancer tumor samples (age range, 37-78; 177 male and 51 female) were prospectively collected from The Oncology Surgery Department of The First Affiliated Hospital of Xi'an Jiaotong University (Xi'an, China) between January 2005 and August 2009. The present study was approved by the Ethical Conduct in Human Research Committee of the First Affiliated Hospital of Xi'an Jiaotong University, and all 228 patients signed written informed consent forms. All 228 tissue samples with matched distant noncancerous esophageal tissue samples were histologically diagnosed. Samples were snap-frozen in liquid nitrogen following resection and stored in liquid nitrogen until use. Tumor stages and histological grades were recorded using the classification guidelines of the American Joint Committee on Cancer 7 (24). Among these 228 patients, 214 patients with esophageal cancer were surgically treated with the same therapeutic strategy; that is, complete tumor resection with negative margins (R0 resection) and extensive lymphadenectomy. The remaining 14 cases were at stage IV of the disease and underwent palliative surgery. Furthermore, following surgery all patients received postoperative chemotherapy with 5 -fluorouracil (5-FU; $425 \mathrm{mg} / \mathrm{m}^{2} 5$-FU daily on days $1-5$, cycled every 28 days), leucovorin $\left(20 \mathrm{mg} / \mathrm{m}^{2}\right.$ of leucovorin on days $\left.1-5\right)$, and 45-50 Gy of radiotherapy (1.8 Gy/day). Patients with only palliative surgery or recurrent disease were treated with ECF adjunctive treatment $\left(50 \mathrm{mg} / \mathrm{m}^{2}\right.$ of Epirubicin on day $1,60 \mathrm{mg} / \mathrm{m}^{2}$ of cisplatin on day $1,200 \mathrm{mg} / \mathrm{m}^{2}$ of 5 -FU continuous infusion over $24 \mathrm{~h}$ daily on days 1-21 for three cycles). All patients were followed up on a regular basis for $>60$ months or until mortality. The last follow-up was conducted in March 2015.

Immunohistochemistry. All tissue specimens were fixed in 10\% buffered formalin at $37^{\circ} \mathrm{C}$ for $12 \mathrm{~h}$ and embedded in paraffin for preparation of consecutive $4-\mu \mathrm{m}$ thick sections. For immunohistochemistry, tissue sections were first deparaffinized and rehydrated, subjected to an antigen retrieval treatment with a pressure cooker, and incubated with $10 \%$ normal goat serum (Qcbio S\&T Co., Ltd., Shanghai, China) at room temperature for $30 \mathrm{~min}$ to block potential non-specific binding of the secondary antibody. Sections were then incubated with a primary mouse anti-human anti-phosphorylated (p)-p38 antibody (cat. no. H00001432-M01, 1:2,500; Abnova, Walnut, CA, USA) at $4^{\circ} \mathrm{C}$ overnight. On the following day, the sections were washed with PBS and further incubated with a secondary goat anti-mouse $\operatorname{IgG}$ at a dilution of 1:200 (cat. no. A-11029; Pierce; Thermo Fisher Scientific, Inc., Waltham, MA, USA) for $30 \mathrm{~min}$ at room temperature and with 3,3'-diaminobenzidine for $15 \mathrm{~min}$ at room temperature as a chromogen. The sections were finally counterstained with hematoxylin solution for $5 \mathrm{~min}$ at room temperature, dehydrated and covered with coverslips. All stained sections were independently evaluated by two investigators and agreement was reached following careful discussion, if discrepancies occurred. P-p38 was scored by the multiplication of the percentage of positive tumor cells and staining intensity as described in our previous study (25). The percentage of positive cells was scored as: $0,0-15 \% ; 1+, 16-30 \% ; 2+, 31-60 \%$; and $3+, 61-100 \%$. Intensity of staining was graded as follows: Grade 0 , negative; $1+$, weak positive; $2+$, moderate positive; and $3+$, strong positive (24). According to these immunohistochemical scores, p-p38 expression was then divided into two groups: Negative or weak p-p38 expression (score $\leq 3$ ); and positive or strong p-p38 expression (score $\geq 4$; Fig. 1). Images of the stained sections were obtained using a light microscope (BX51) equipped with a digital camera (PD71; Olympus Corporation, Tokyo, Japan).

Cell lines, culture, gene transfection and treatment. Human esophageal cancer Eca-109 and TE-1 cell lines were obtained from The Type Culture Collection of the Chinese Academy of Sciences (Shanghai, China). Cells were cultured in RPMI-1640 medium (Gibco; Thermo Fisher Scientific, Inc.) supplemented with $10 \%$ heat-inactivated fetal bovine serum (Hyclone; GE Healthcare Life Sciences, Logan, UT, USA), $100 \mathrm{U} / \mathrm{ml}$ of penicillin and $100 \mathrm{mg} / \mathrm{ml}$ of streptomycin (both from Gibco; Thermo Fisher Scientific, Inc.) at $37^{\circ} \mathrm{C}$ in a $5 \%$ $\mathrm{CO}_{2}$ incubator. In order to manipulate gene expression in cells, plasmids carrying p-p38 cDNA were separately transfected into these two esophageal cancer cell lines using X-treme HP (Roche Applied Science, Mannheim, Germany), according to manufacturer's instructions. After $48 \mathrm{~h}$ of transfection at $37^{\circ} \mathrm{C}$, G418-sulfate (700 ng/ $\mu 1$ for Eca-109 and $800 \mathrm{ng} / \mu 1$ for TE-1; Sigma-Aldrich; Merck KGaA, Darmstadt, Germany) was added to the cell culture medium throughout the experiment. Cells were fed three times weekly and periodically assessed by western blotting to ensure transgene expression. Thalidomide (25 mg/tablet; ChangZhouZhiYao Jiangsu, China) was ground, dissolved, filtered and adjusted to $2,000 \mathrm{mM}$ with RPMI-1640 medium. Prior to treatment, the thalidomide was diluted into $200 \mathrm{mM}$, and incubated for $\leq 72 \mathrm{~h}$ prior to testing. SB203580 (S8307; Sigma-Aldrich; Merck KGaA) was diluted using dimethyl sulfoxide into $1,000 \mu \mathrm{g} / \mathrm{ml}$ and further diluted into $0.05 \mu \mathrm{g} / \mathrm{ml}$ using RPMI-1640 medium prior to cell $\mathrm{p} 38$ blocking incubation for $8 \mathrm{~h}$.

Protein extraction and western blot analysis. Cells were lysed with modified RIPA buffer (50 mM of Tris, $150 \mathrm{mM}$ of $\mathrm{NaCl}$, $1 \%$ Triton X-100, $1 \%$ sodium deoxycholate, and $0.1 \%$ SDS) containing $25 \mu \mathrm{g} / \mathrm{ml}$ of leupeptin, $1 \mathrm{mM}$ of sodium orthovanadate, $2 \mathrm{mM}$ of EDTA and $1 \mathrm{mM}$ of phenylmethylsulfonyl fluoride. The concentration of the protein samples was determined using a BCA kit (Beyotime Institute of Biotechnology, Beijing, China). A total of $20 \mu \mathrm{g}$ of each protein sample was loaded onto an $8 \%$ SDS-PAGE gel, electrophoresed and blotted 
Table I. Associations between p38 expression and clinicopathological features from patients with esophageal cancer ( $\mathrm{n}=228$ ).

\begin{tabular}{|c|c|c|c|c|c|}
\hline Variables & No. of cases & p-p38-positive & P-value (univariate) & P-value (multivariate) & Risk ratio $(95 \% \mathrm{CI})$ \\
\hline Age (years) & & & 0.116 & & \\
\hline$\leq 59$ & 134 & $86(64.1)$ & & & \\
\hline$>59$ & 94 & $71(75.5)$ & & & \\
\hline Sex & & & 0.08 & & \\
\hline Male & 177 & $127(71.8)$ & & & \\
\hline Female & 51 & $30(58.8)$ & & & \\
\hline Histological types & & & 0.558 & & \\
\hline Squamous & 206 & $142(68.9)$ & & & \\
\hline Adenocarcinoma & 22 & $15(68.2)$ & & & \\
\hline Invasion & & & 0.032 & 0.171 & \\
\hline $\mathrm{T} 1$ & 22 & $12(54.5)$ & & & \\
\hline $\mathrm{T} 2$ & 31 & $18(58.1)$ & & & \\
\hline $\mathrm{T} 3$ & 131 & $92(70.2)$ & & & \\
\hline $\mathrm{T} 4$ & 38 & $33(86.8)$ & & & \\
\hline Lymph node & & & 0.048 & 0.955 & \\
\hline No & 127 & $83(65.4)$ & & & \\
\hline $\mathrm{N} 1$ & 83 & $59(71.1)$ & & & \\
\hline $\mathrm{N} 2$ & 18 & $15(83.3)$ & & & \\
\hline Metastasis & & & 0.024 & 0.086 & \\
\hline Negative & 212 & $144(67.9)$ & & & \\
\hline Positive & 16 & $13(81.2)$ & & & \\
\hline Depression status & & & 0.001 & 0.040 & $2.382(0.503-2.978)$ \\
\hline None & 38 & $16(42.1)$ & & & \\
\hline Mild & 31 & $15(48.4)$ & & & \\
\hline Modest & 76 & $59(77.6)$ & & & \\
\hline Severe & 60 & $47(78.3)$ & & & \\
\hline Chemotherapy & & & 0.323 & & \\
\hline $\mathrm{CR}$ & 16 & $12(75.0)$ & & & \\
\hline $\mathrm{PR}$ & 64 & $43(67.2)$ & & & \\
\hline $\mathrm{SD}$ & 40 & $27(67.5)$ & & & \\
\hline $\mathrm{PD}$ & 70 & $57(81.4)$ & & & \\
\hline Recurrence & & & 0.003 & 0.38 & \\
\hline OS & & & $<0.001$ & $<0.001$ & $0.903(0.029-12.623)$ \\
\hline
\end{tabular}

CR, complete response; PR, partial response; $\mathrm{SD}$, stable disease; $\mathrm{PD}$, progressive disease; OS, overall survival time.

onto a polyvinylidene difluoride membrane (Sigma-Aldrich; Merck KGaA). The membranes were blotted with the first antibody (anti-p-p38) overnight at $4^{\circ} \mathrm{C}$ (cat. no. AM063; Beyotime, Zhejiang, China), anti-IDO (cat.no.H00003620-B01P; Abnova, Walnut, CA, USA), anti-Ku80 (cat. no. BS2692; Bioworld Technology, Inc., St. Louis Park, MN, USA) and anti- $\beta$-actin antibody (cat. no. MAB12983; Abnova) and with a secondary antibody at room temperature for $1 \mathrm{~h}$. Immunoreactivity was detected using an enhanced chemiluminescence system (Xi'an Jiaotong University) and normalized to $\beta$-actin.

Cell viability assay. Cell viability was assessed using an MTT assay. Cells with stably transfected p-p38 and 48 h of transfection with plasmid were seeded into 96 -well plates at a density of $3 \times 10^{3}$ cells/well, and treated with or without thalidomide at $0.2 \mathrm{mg} / \mathrm{l}$ for $\leq 3$ days. At the end of the experiments, $20 \mu \mathrm{l}$ of MTT $(0.5 \mathrm{mg} / \mathrm{ml}$ in PBS) were added to the cells, incubated for $4 \mathrm{~h}$ at $37^{\circ} \mathrm{C}$, the growth medium was discarded, and $100 \mu \mathrm{l}$ of DMSO was added into each well. Following agitation for $10 \mathrm{~min}$ at $37^{\circ} \mathrm{C}$ on a shaker, the absorbance rate was read at $550 \mathrm{~nm}$ with a scanning microtiter (PerkinElmer, Inc., Waltham, MA, USA). Data was summarized as the percentage of control compared with untreated cells.

Cell apoptosis analyses. Apoptosis in these cells treated with or without thalidomide was evaluated using flow cytometric techniques using an Annexin V-FLUOS Staining kit (Roche Applied Science), according to manufacturer's instructions. 
A

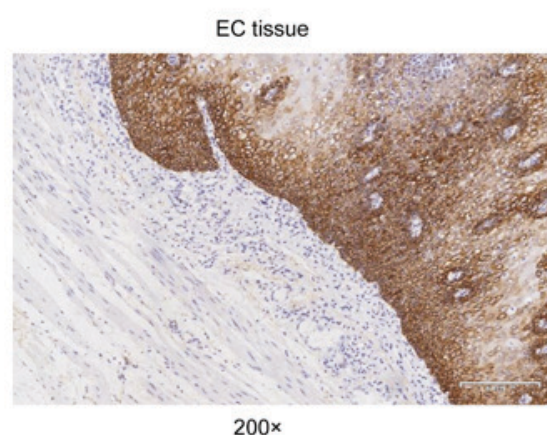

C

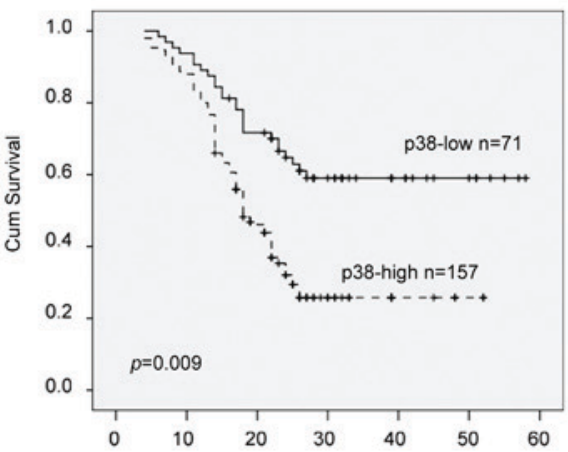

$\mathrm{E}$

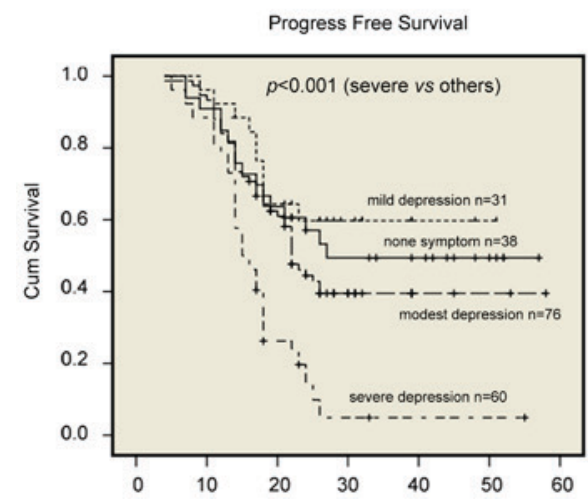

B

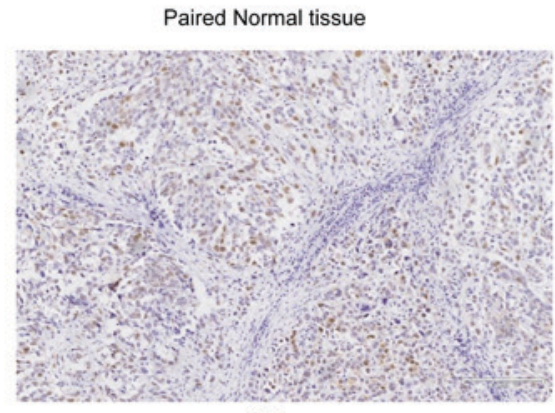

$200 \times$

D

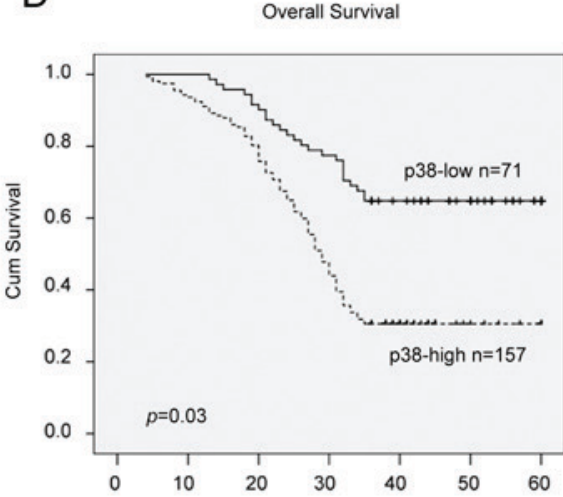

$\mathrm{F}$

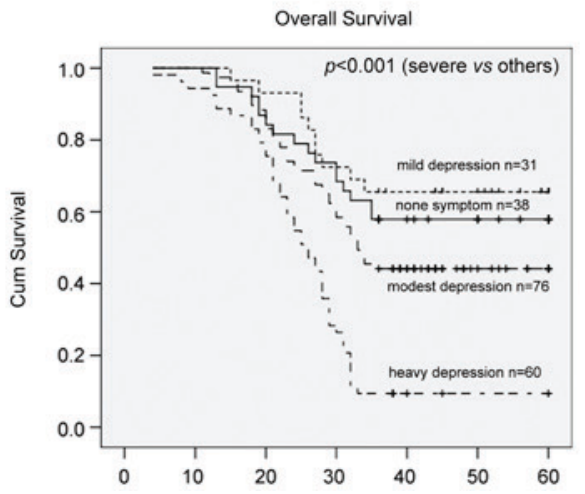

Figure 1. Immunohistochemical analysis of p-p38 expression in (A) EC and (B) paired normal tissue samples. Positive staining is indicated by a brown nuclear color. Kaplan-Meier curve analyses for (C) disease-free and (D) overall survival of patients with EC with regards to p-p38. Kaplan-Meier curve analyses for (E) disease-free and $(\mathrm{F})$ overall survival of patients with EC with regards to depression. EC, esophageal cancer; cum, cumulative.

ELISA test. ELISA kits (Applygen Technologies, Inc., Beijing, China) were used in order to test glucose consumption between parental esophageal cancer cells and p38-transfected ones. Glucose levels were determined in the supernatant of the medium at 0, 24, 48 and $72 \mathrm{~h}$. Glucose levels were determined using the glucose oxidase method (26), according to manufacturer's instructions. Furthermore, 2-deoxy-D-glucose (2-DG; $10 \mathrm{mM}$ ) was used to block glucose metabolism $(16,27)$ and the dependence to glucose consumption was analyzed.

Statistical analysis. The $\chi^{2}$ test was performed to compare the expression of p-p38 with clinicopathological data from patients. Then, Spearman and logistic regression analyses were utilized to compare the expression of p-p38 between tumor and adjacent normal tissues. Kaplan-Meier curve and logical rank test were used to analyze survival data of the patients. All in vitro data are presented as the mean of $\geq 3$ individual experiments \pm standard error of the mean, which was statistically analyzed using the Student's t-test. All statistical analyses were conducted using SPSS 13.0 software (SPSS, Inc., Chicago, IL, USA). P<0.05 was considered to indicate a statistically significant difference.

\section{Results}

Protein expression of 38 is associated with poor clinical outcome of esophageal cancer patients. In the present study, the protein expression of p38 was detected in a total of 228 patients with esophageal cancer, and the corresponding normal tissues were analyzed using immunohistochemistry. It was identified that the protein expression of p38 
Table II. Log-rank and Cox proportional hazards regression model of prognostic variables for progress free survival of patients with esophageal cancer.

\begin{tabular}{lccc}
\hline Prognostic variable & P-value (univariate) & P-value (multivariate) & Risk ratio (95\% CI) \\
\hline Age (years) & $<0.001$ & 0.376 & \\
Sex & 0.243 & 0.264 & $1.534(0.256-6.814)$ \\
Stage (IA-IV) & $<0.001$ & 0.008 & $1.186(0.359-4.886)$ \\
p38 & $<0.001$ & 0.001 & $4.245(0.158-9.617)$ \\
T & $<0.001$ & 0.914 & \\
N & $<0.001$ & 0.025 & 0.056 \\
M & $<0.001$ & 0.327 & $0.433(0.361-5.377)$ \\
Depression status & $<0.001$ & 0.045 & $0.455(0.216-13.365)$ \\
Mild & & 0.001 & 0.497 \\
Modest & & 0.01 & \\
Severe & & & \\
Chemotherapy & & & \\
\hline
\end{tabular}

T, tumor; N, node; M, metastasis; CI, confidence interval.

Table III. Log-Rank and Cox proportional hazards regression model of prognostic variables for overall survival of patients with esophageal cancer.

\begin{tabular}{lccc}
\hline Prognostic variable & P-value (univariate) & P-value (multivariate) & Risk ratio (95\% CI) \\
\hline Age (years) & 0.001 & 0.273 & \\
Sex & 0.433 & 0.129 & $1.677(0.238-4.717)$ \\
Stage (IA-IV) & $<0.01$ & 0.03 & \\
p38 & $<0.01$ & 0.212 & $3.66(0.406-10.192)$ \\
T & $<0.01$ & 0.754 & \\
N & $<0.01$ & 0.001 & 0.002 \\
M & $<0.01$ & 0.128 & $0.433(0.361-5.377)$ \\
Depression status & $<0.01$ & 0.02 & $0.455(0.216-13.365)$ \\
Mild & & $<0.01$ & $1.551(0.106-17.219)$ \\
Modest & & $<0.01$ & \\
Severe & $<0.01$ & & \\
Chemotherapy & & & \\
\hline
\end{tabular}

T, tumor; N, node; M, metastasis; CI, confidence interval.

was significantly upregulated in esophageal cancer tissues, compared with paired non-cancerous tissues (Fig. 1); that is, p38 protein was expressed in $157 / 228$ (68.9\%) esophageal cancer tissues, whereas 35/228 (15.4\%) matched adjacent non-cancer tissues were $\mathrm{p} 38$-positive $(\mathrm{P}<0.01)$. Furthermore, p38 expression was identified to be significantly associated with tumor invasion $(\mathrm{P}=0.032)$, lymph nodes metastasis $(\mathrm{P}=0.048)$, tumor recurrence $(\mathrm{P}=0.003)$, depression $(\mathrm{P}=0.001)$ and overall survival $(\mathrm{P}<0.01)$ of patients with esophageal cancer (Table I). In addition, multivariate analysis revealed that $\mathrm{p} 38$ was associated with overall survival and depression (Table I).

Kaplan-Meier curve analysis was performed, and the data revealed that p38 expression was significantly associated with poor overall $(\mathrm{P}=0.03)$ and disease-free $(\mathrm{P}=0.009)$ survival rates for patients with esophageal cancer. In addition, survival was affected by metastasis $(\mathrm{P}=0.001)$, depression $(\mathrm{P}=0.002)$ and chemotherapy $(\mathrm{P}<0.01)$ based on log-rank survival analysis (Tables II and III). Multivariate stepwise logistic regression analyses revealed that the protein expression of $\mathrm{p} 38$, tumor invasion and depression were all independent predictors for the survival time of patients.

Transfection of p38 increases cell proliferation and glucose dependence in esophageal cancer cell lines Eca-109, and TE-1. As previously reported (18), p38 can enhance cell proliferation in esophageal cancer cell lines. In order to investigate the 
A
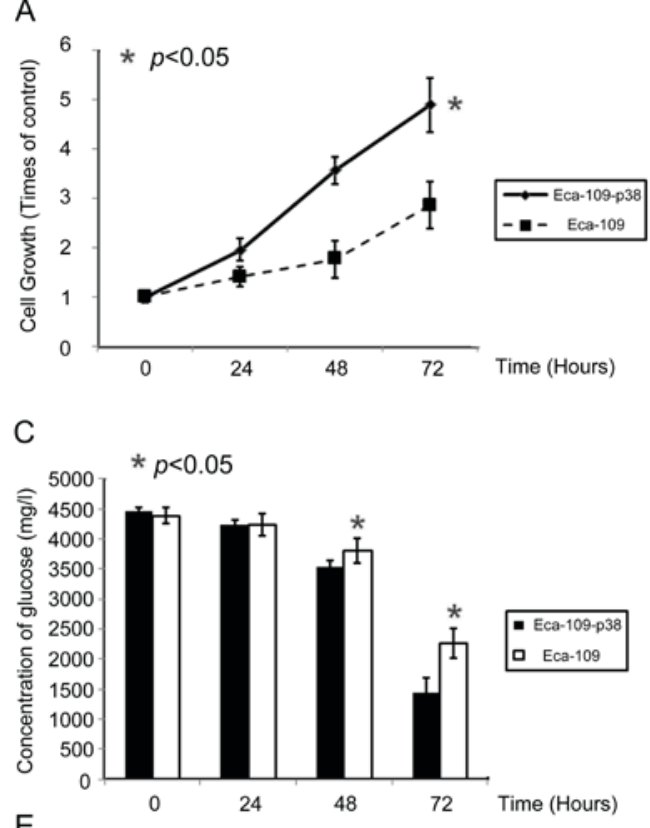

$\mathrm{E}$

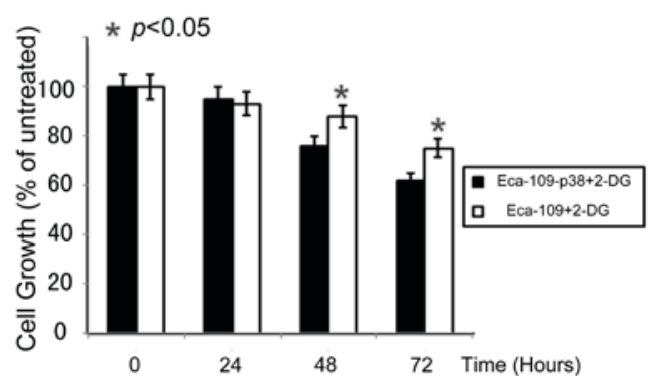

B

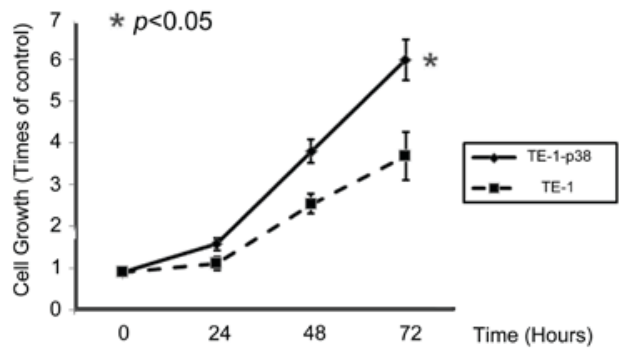

D
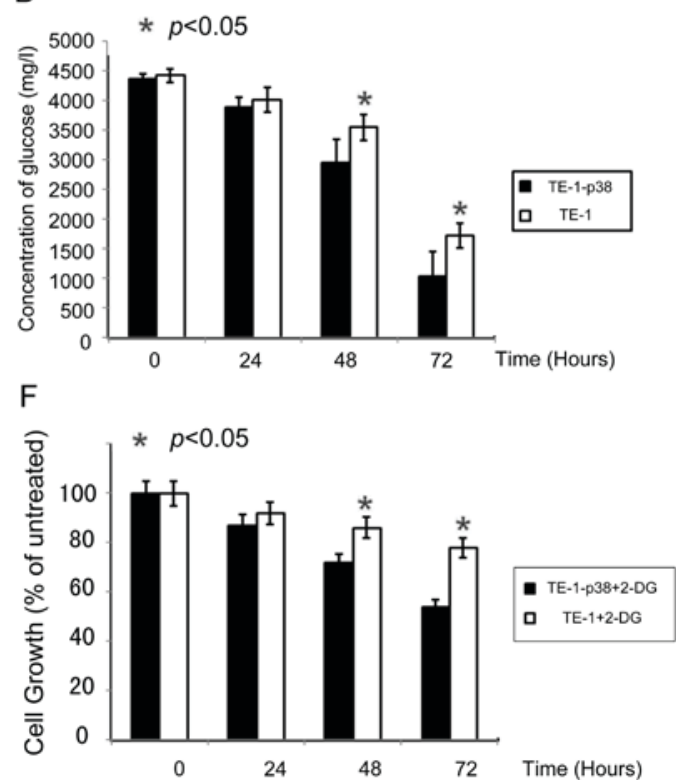

Figure 2. Effects of p38 expression on the regulation of esophageal cancer cell viability. Cell proliferation on MTT assay in esophageal cancer (A) Eca-109 and (B) TE-1 cells. Medium glucose detection in different expression levels of p38 on (C) Eca-109 and (D) TE-1 cells. Effect of 2-DG treatment on the growth of (E) Eca-109 and (F) TE-1 cells with different expression levels of p38. ${ }^{*} \mathrm{P}<0.05 .2$-DG, 2-deoxy-D-glucose.

potential of p38 to enhance cell growth in esophageal cancer cells (Eca-109 and TE-1), cell viability was measured using an MTT assay following transfection of the p38 gene. Elevated p38 expression increased Eca-109 and TE-1 proliferation in a time-dependent manner. 338 had a definite effect on esophageal cancer cell growth. With the upregulation of p38, cell growth was promoted at a statistically significant level on days two and three (Fig. 2A and B).

Cells with elevated p38 exhibited a significant increase in glucose consumption (Fig. 2C and D). This indicates that p38 may influence cell glycolysis in esophageal cancer cells directly. Growth of Eca-109 and TE-1 was inhibited by incubation with 2-DG in a time-dependent manner (Fig. 2E and F); the growth of cells with elevated p38 expression was inhibited by 34 and $42 \%$ using 2-DG at 72 h. Parental Eca-109 and TE-1 cells (in which p38 was normal) were significantly less sensitive to 2-DG compared with cells with enhanced p38 expression.

Increased p38 resist esophageal cancer cells to thalidomide-induced cell death. Since p38 protein is able to regulate chemotherapy treatment (26), whether or not p38 expression can affect esophageal cancer cell response to thalidomide treatment was determined. Following the transfection of p38 protein in esophageal cancer cells, treatment $200 \mathrm{mM}$ of thalidomide for $72 \mathrm{~h}$ decreased the viability of parental esophageal cancer cells. The upregulation of p38 in esophageal cancer cells significantly reduced the decrease in cell viability caused by thalidomide treatment $(\mathrm{P}<0.05$; Fig. $3 \mathrm{~A}$ and $\mathrm{B})$.

Furthermore, the tumor cell apoptosis assay revealed that the average apoptotic cell fraction markedly decreased in p38 overexpression cells compared with that in parental cells (Fig. 3C). Following treatment with thalidomide for $24 \mathrm{~h}$, cells with elevated p38 expression were associated with a decrease in apoptosis in Eca-109 (81.9\%) and TE-1 (41.2\%) cells, respectively, compared with parental controls. This finding suggests that p38 serves a role in tumor cell resistance to thalidomide-induced apoptosis.

In order to discover the mechanism involved in p38-induced resistance, $\mathrm{Ku}$ autoantigen $80 \mathrm{kDa}(\mathrm{Ku} 80)$ was detected and recruited following DNA fraction. After $48 \mathrm{~h}$ of incubation, Ku80 in normal cells was markedly lower compared with in p38-transfected Eca-109 and TE-1 cells (Fig. 3D), although there was no observable difference prior to treatment with thalidomide.

P38 expression is associated with higher IDO levels and depression. Coltella et al (15) reported that p38 was essential in inducing the expression of IDO, a depression associated gene. In order to investigate whether or not p38 alone could 
A

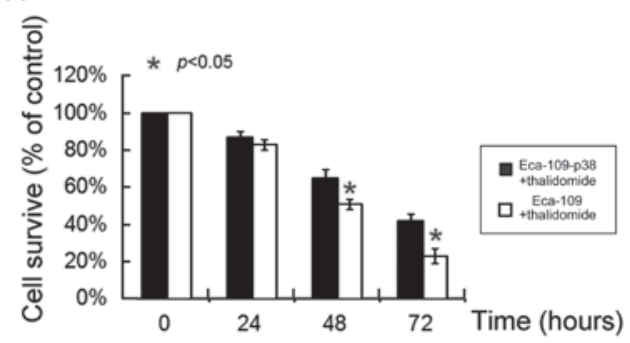

B

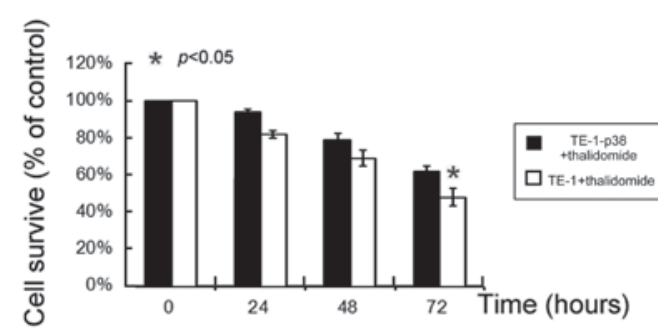

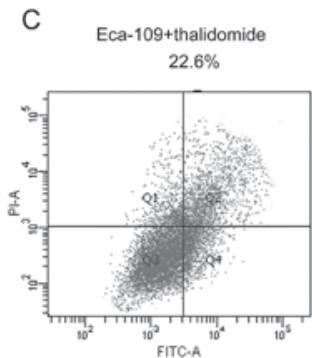

C

TE-1+thalidomide $14.8 \%$

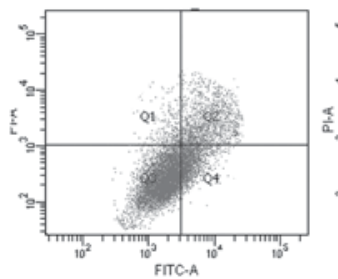

Eca-109-p38+thalidomide $18.5 \%$

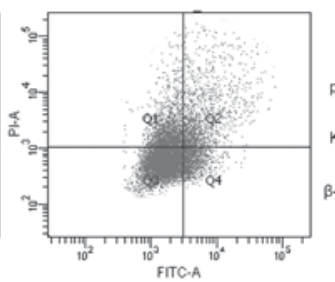

TE-1-p38+thalidomide $6.1 \%$

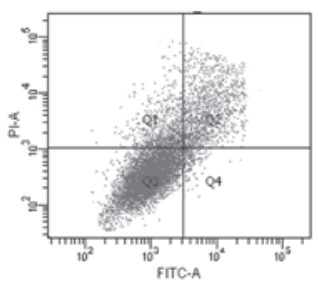

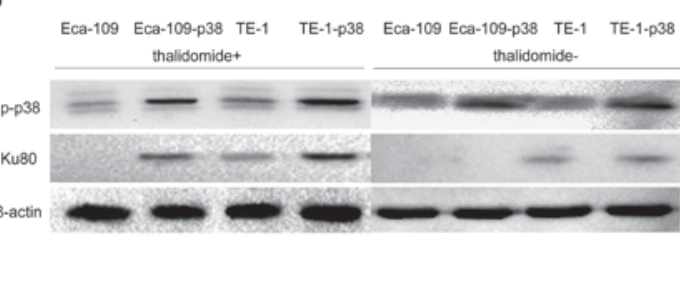

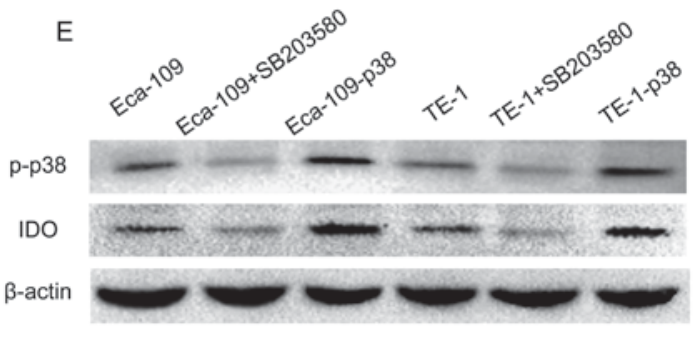

Figure 3. Effects of p38 expression on the regulation of tumor cell sensitivity to thalidomide treatment. MTT assay for the survival rate of (A) Eca-109 and (B) TE-1 cells. (C) Flow cytometric apoptosis assay of Eca-109 and TE-1 cells. (D) Western blotting for Ku80 expression following treatment with or without thalidomide in cells with different p38 expression levels. (E) p38 expression in esophageal cancer cells is positively associated with IDO expression. Ku80, Ku autoantigen $80 \mathrm{kDa}$; p, phosphorylated; IDO, indoleamine 2,3-dioxygenase; FITC, fluorescein isothiocyanate; PI, propidium iodide.

increase IDO expression in esophageal cancer cells, western blotting in Eca-109 and TE-1 cells were performed without the addition of LPS. Results revealed that IDO expression in Eca-109 and TE-1 was markedly upregulated by p38 transfection compared with in parental cell lines (Fig. 3E). Blocking p38 using SB203580 markedly reduced IDO expression compared with parental cells (Fig. 3E).

In order to determine whether or not the IDO gene was associated with depression, the medical record of 228 esophageal cancer patients were reviewed and the Zung Self-Rating Depression Scale was used to assess the status of depression. The depression status of 205 patients could be retrieved from patients or their relatives. From the data obtained, it was identified that 167 patients (81.5\%) had depression. Based on the analysis, p38 expression was identified to be associated with depression ( $\mathrm{P}=0.04$; Table I). Logistic regression analyses revealed that recurrence was associated with poor overall $(\mathrm{P}=0.002)$ and disease-free $(\mathrm{P}=0.005)$ survival rates for patients with esophageal cancer (Table II; Fig. 1E and F).

\section{Discussion}

In the present study, it was demonstrated that p38 MAPK predicts poor prognosis in esophageal cancer and increases IDO expression independent of LPS. It was also revealed that p38 MAPK mediates cell proliferation, contributes to the development of thalidomide resistance in vitro, enhances cellular dependence on glucose, and increases p38-MAPK upregulated IDO gene expression, which is associated with depressive symptoms, as confirmed by multiple studies $(28,29)$.

Recent studies of esophageal cancer on p38-MAPK remain limited. Zheng et al (30) reported that in cancer cells in vitro, p38 serves as an oncogene that promotes cell growth; while at a stage prior to carcinogenesis, it suppress tumor growth. Another study focusing on cell cycle revealed that $\mathrm{p} 38$ participates in cancer $\mathrm{G}_{1} / \mathrm{G}_{0}$-phase arrest induced by obatoclax (18). In other cancer types, p38-MAPK also served as a paradox; in which certain results demonstrated cancer promoting, and others revealed suppressive functions of p38 (31). The results of the present study in cancer tissue and cells confirmed the findings of the aforementioned studies. In addition, the use of thalidomide was assessed in order to assess the possibility of using this anti-angiogenesis agent as an anticancer drug for the treatment of esophageal cancer (32). The results of the present study indicated that thalidomide was able to induce apoptosis in esophageal cancer cell types Eca-109 and TE-1, although its mechanism remains to be elucidated.

Signaling studies on depressive symptoms revealed that the expression of IDO or decreased MAP kinase phosphatase 1 in the hippocampus contributes to depression (33). In the present in vitro study, it was demonstrated that p38-MAPK was not only an independent predictor of poor outcome in esophageal 
cancer, but also aggravates cancer-associated depression by enhancing IDO expression. In fact, almost half of the patients enrolled in the study were not informed that they suffered from esophageal cancer, as requested by their relatives, who in these cases held power of attorney and therefore medical rights over the patient. This may suggest that cancer itself may trigger or aggravate depressive symptoms in these patients, whether they have knowledge of the disease or not. In addition, the findings of the present study suggest that patients with increased p38 or IDO expression are prone to develop depression and likely to require antidepressants. For those with decreased IDO, a placebo effect may exist to a certain extent, which requires further research (34).

However, it should be noted that the present study was retrospective in nature. More detailed medical records and follow-ups are required to understand the psychological status of these patients. In addition, all factors that contribute to cancer-associated depression were not included. In fact, a change in eating habits following a surgical operation or forbidding a patient to smoke is enough for a patient with a heavy addiction to exhibit depressive symptoms, as well as surgical complications. These problems could be resolved with detailed clinical history, in which more cases would be enrolled in our next study. Notwithstanding its limitations, the present study does suggest the significance of esophageal-associated depressive symptoms, which may be induced by p38 and IDO expression. Furthermore, this study sheds new light on the role of p38 and its potential application in the clinic. Further in vitro and in vivo studies are required to determine the association between $\mathrm{p} 38$, IDO, and esophageal cancer in depression.

\section{Acknowledgements}

The present study was supported by the National Natural Scientific Foundation of China (grant no. 81501826).

\section{References}

1. Rubenstein JH and Shaheen NJ: Epidemiology, diagnosis, and management of esophageal adenocarcinoma. Gastroenterology 149: 302-317, 2015.

2. Mortensen MB: Avoiding complications in esophageal cancer surgery. Minerva Chir 68: 341-352, 2013.

3. Brescia AA, Broderick SR, Crabtree TD, Puri V, Musick JF, Bell JM, Kreisel D, Krupnick AS, Patterson GA and Meyers BF: Adjuvant therapy for positive nodes after induction therapy and resection of esophageal cancer. Ann Thorac Surg 101: 200-210, 2016.

4. Pozza A, Erroi FR, Scarpa M, Polese L, Rampazzo L and Norberto L: Palliative therapy for esophageal cancer: Laser therapy alone is associated with a better functional outcome. Updates Surg 67: 61-67, 2015.

5. Wilson KG, Chochinov HM, Skirko MG, Allard P, Chary S, Gagnon PR, Macmillan K, De Luca M, O'Shea F, Kuhl D, et al: Depression and anxiety disorders in palliative cancer care. J Pain Symptom Manage 33: 118-129, 2007.

6. Grabsch B, Clarke DM, Love A, McKenzie DP, Snyder RD, Bloch S, Smith G and Kissane DW: Psychological morbidity and quality of life in women with advanced breast cancer: A cross-sectional survey. Palliat Support Care 4: 47-56, 2006.

7. Pelletier G, Verhoef MJ, Khatri N and Hagen N: Quality of life in brain tumor patients: The relative contributions of depression, fatigue, emotional distress, and existential issues. J Neurooncol 57: 41-49, 2002.

8. Breitbart W: Identifying patients at risk for, and treatment of major psychiatric complications of cancer. Support Care Cancer 3: 45-60, 1995.
9. Irving G and Lloyd-Williams M: Depression in advanced cancer. Eur J Oncol Nurs 14: 395-399, 2010.

10. Kadan-Lottick NS, Vanderwerker LC, Block SD, Zhang B and Prigerson HG: Psychiatric disorders and mental health service use in patients with advanced cancer: A report from the coping with cancer study. Cancer 104: 2872-2881, 2005.

11. Kumar B, Koul S, Petersen J, Khandrika L, Hwa JS, Meacham RB, Wilson S and Koul HK: p38 mitogen-activated protein kinase-driven MAPKAPK2 regulates invasion of bladder cancer by modulation of MMP-2 and MMP-9 activity. Cancer Res 70: 832-841, 2010

12. Xiong S, Grijalva R, Zhang L, Nguyen NT, Pisters PW, Pollock RE and Yu D: Up-regulation of vascular endothelial growth factor in breast cancer cells by the heregulin-beta1-activated p38 signaling pathway enhances endothelial cell migration. Cancer Res 61: 1727-1732, 2001.

13. Kumar V, Behera R, Lohite K, Karnik S and Kundu GC: p38 kinase is crucial for osteopontin-induced furin expression that supports cervical cancer progression. Cancer Res 70: 10381-10391, 2010.

14. Guo X, Ma N, Wang J, Song J, Bu X, Cheng Y, Sun K, Xiong H, Jiang G, Zhang B, et al: Increased p38-MAPK is responsible for chemotherapy resistance in human gastric cancer cells. BMC Cancer 8: 375, 2008.

15. Coltella N, Rasola A, Nano E, Bardella C, Fassetta M, Filigheddu N, Graziani A, Comoglio PM and Di Renzo MF: p38 MAPK turns hepatocyte growth factor to a death signal that commits ovarian cancer cells to chemotherapy-induced apoptosis. Int J Cancer 118: 2981-2990, 2006.

16. Looby E, Abdel-Latif MM, Athié-Morales V, Duggan S, Long A and Kelleher D: Deoxycholate induces COX-2 expression via Erk1/2-, p38-MAPK and AP-1-dependent mechanisms in esophageal cancer cells. BMC Cancer 9: 190, 2009.

17. Yousif NG, Al-Amran FG, Hadi N, Lee J and Adrienne J: Expression of IL-32 modulates NF-kB and p38 MAP kinase pathways in human esophageal cancer. Cytokine 61: 223-227, 2013.

18. Zhong D, Gu C, Shi L, Xun T, Li X, Liu S and Yu L: Obatoclax induces G1/G0-phase arrest via p38/p21(waf1/Cip1) signaling pathway in human esophageal cancer cells. J Cell Biochem 115: 1624-1635, 2014.

19. Zoga M, Oulis P, Chatzipanagiotou S, Masdrakis VG, Pliatsika P, Boufidou F, Foteli S, Soldatos CR, Nikolaou C and Papageorgiou C: Indoleamine 2,3-dioxygenase and immune changes under antidepressive treatment in major depression in females. In Vivo 28: 633-638, 2014.

20. Zhou W, Dantzer R, Budac DP, Walker AK, Mao-Ying QL, Lee AW, Heijnen CJ and Kavelaars A: Peripheral indoleamine 2,3-dioxygenase 1 is required for comorbid depression-like behavior but does not contribute to neuropathic pain in mice. Brain Behav Immun 46: 147-153, 2015.

21. Liu WL, Lin YH, Xiao H, Xing S, Chen H, Chi PD and Zhang G: Epstein-Barr virus infection induces indoleamine 2,3-dioxygenase expression in human monocyte-derived macrophages through $\mathrm{p} 38 /$ mitogen-activated protein kinase and NF- $\mathrm{KB}$ pathways: Impairment in T cell functions. J Virol 88: 6660-6671, 2014.

22. Fujigaki H, Saito K, Fujigaki S, Takemura M, Sudo K, Ishiguro H and Seishima M: The signal transducer and activator of transcription 1alpha and interferon regulatory factor 1 are not essential for the induction of indoleamine 2,3-dioxygenase by lipopolysaccharide: Involvement of p38 mitogen-activated protein kinase and nuclear factor-kappaB pathways, and synergistic effect of several proinflammatory cytokines. J Biochem 139: 655-662, 2006.

23. Fu X, Lawson MA, Kelley KW and Dantzer R: HIV-1 Tat activates indoleamine 2,3 dioxygenase in murine organotypic hippocampal slice cultures in a p38 mitogen-activated protein kinase-dependent manner. J Neuroinflammation 8: 88, 2011.

24. Nomura M, Shitara K, Kodaira T, Hatooka S, Mizota A, Kondoh C, Yokota T, Takahari D, Ura T and Muro K: Prognostic impact of the 6th and 7th American Joint Committee on Cancer TNM staging systems on esophageal cancer patients treated with chemoradiotherapy. Int J Radiat Oncol Biol Phys 82: 946-952, 2012.

25. Cheng Y, Li K, Diao D, Zhu K, Shi L, Zhang H, Yuan D, Guo Q, Wu X, Liu D and Dang C: Expression of KIAA0101 protein is associated with poor survival of esophageal cancer patients and resistance to cisplatin treatment in vitro. Lab Invest 93: 1276-1287, 2013. 
26. Burrin JM and Price CP: Performance of three enzymic methods for filter paper glucose determination. Ann Clin Biochem 21: 411-416, 1984.

27. Cheng Y, Diao D, Zhang H, Guo Q, Wu X, Song Y and Dang C: High glucose-induced resistance to 5 -fluorouracil in pancreatic cancer cells alleviated by 2-deoxy-D-glucose. Biomed Rep 2: 188-192, 2014.

28. Wichers $\mathrm{MC}$ and Maes $\mathrm{M}$ : The role of indoleamine 2,3-dioxygenase (IDO) in the pathophysiology of interferonalpha-induced depression. J Psychiatry Neurosci 29: 11-17, 2004

29. Kohl C and Sperner-Unterweger B: IDO and clinical conditions associated with depressive symptoms. Curr Drug Metab 8: 283-287, 2007.

30. Zheng ST, Zhang CS, Qin X, Gen YH, Liu T, Sheyhidin I and Lu XM: The status of phosphorylated p38 in esophageal squamous cell carcinoma. Mol Biol Rep 39: 5315-5321, 2012.
31. Pal A, Huang W, Li X, Toy KA, Nikolovska-Coleska Z and Kleer CG: CCN6 modulates BMP signaling via the Smad-independent TAK1/p38 pathway, acting to suppress metastasis of breast cancer. Cancer Res 72: 4818-4828, 2012.

32. Yu JP, Sun SP, Sun ZQ, Ni XC, Wang J, Li Y, Hu LJ and Li DQ: Clinical trial of thalidomide combined with radiotherapy in patients with esophageal cancer. World J Gastroenterol 20: 5098-5103, 2014

33. Sun YR, Wang XY, Li SS, Dong HY and Zhang XJ: $\beta$-asarone from Acorus gramineus alleviates depression by modulating MKP-1. Genet Mol Res 14: 4495-4504, 2015.

34. Cuijpers P and Cristea IA: What if a placebo effect explained all the activity of depression treatments? World Psychiatry 14: 310-311, 2015. 